\title{
DEMANDA HÍDRICA DO MARACUJAZEIRO AMARELO (Passiflora edulis Sims f. flavicarpa Deg.)
}

\author{
Ana Alexandrina Gama da Silva \\ Embrapa Tabuleiros Costeiros, CP 44, CEP 49025-040, Aracaju, SE. E-mail: \\ anagama@cpatc.embrapa.br \\ Antonio Evaldo Klar \\ Departamento de Engenharia Rural, Faculdade de Ciências Agronômicas, Universidade Estadual \\ Paulista, CP 237, CEP 18603-970,Botucatu,SP.E-mail: klar@fca.unesp.br \\ Pesquisador Cientifico do CNPq
}

\section{RESUMO}

Determinou-se à demanda hídrica e o coeficiente de cultivo $(\mathrm{Kc})$ do maracujá amarelo (Passiflora edulis Sims f. flavicarpa Deg.), seleção Sul-Brasil, cultivado sob irrigação localizada, no município de Botucatu-SP $\left(22^{\circ} 51^{\prime} \mathrm{S}, 48^{\circ} 26^{\prime} \mathrm{W}\right)$. A evapotranspiração máxima da cultura (ETc) e a evapotranspiração de referência (ETo) foram medidas em lisímetros de nível de lençol freático constante, durante o período de 29 de setembro de 2000 a 20 de julho de 2001 . Os valores da ETc e ETo foram de $954,98 \mathrm{~mm}$ e $1.069,21 \mathrm{~mm}$, respectivamente, durante todo o período medido. Os valores de Kc variaram de 0,42 a 1,12, com os valores máximos registrados entre 150 e 210 dias após o transplantio das mudas no campo (DAT), período correspondente aos estádios fenológicos de florescimento e formação dos frutos.

UNITERMOS: Passiflora edulis, evapotranspiração, coeficiente de cultivo (Kc).

\section{SILVA, A.A.G. da, KLAR, A.E. YELLOW PASSION FRUIT (Passiflora edulis Sims f. flavicarpa Deg.) CROP: WATER DEMAND.}

\section{ABSTRACT}

Crop water demand and crop water coefficient $(\mathrm{Kc}=\mathrm{ETc} / \mathrm{ETo})$ of yellow passion fruit were evaluated in constant level lysimeters under drip irrigation from September 21, 2000 to July 31, 2001 in Botucatu-SP. The maximum crop water demand (ETc) and the Reference Evapotranspiration (ETo), measured by lysimeters, were $954.98 \mathrm{~mm}$ and $1,069.21 \mathrm{~mm}$, respectively, during all period measured. The values of Kc varied from 0.42 to 1.12 with maximum values registered from 150 to 210 days following transplanting during flowering and fruit formation phases.

KEYWORDS: Passiflora edulis, evapotranspiration, crop coefficient (Kc). 


\section{INTRODUÇÃO}

As plantas de maracujazeiro cultivadas são pouco resistentes ao estresse hídrico e têm sido reportadas como plantas por necessitarem de grande quantidade de água para o seu desenvolvimento em potencial (MENZEL et al. 1986; STAVELY \& WOLSTENHOLME, 1990). Resultados de pesquisas realizadas por Martins (1998), Carvalho et al. (2000) e Sousa (2000) mostram que os rendimentos máximos da cultura (entre 35 a 45 toneladas/hectare) foram obtidos experimentalmente com um consumo de água com irrigação suplementar, em torno de 1300 a $1400 \mathrm{~mm}^{\mathrm{ano} \mathrm{a}^{-1}}$. Na literatura são poucos os trabalhos que tratam sobre o consumo de água do maracujazeiro: Alencar (2000), medindo a evapotranspiração do maracujazeiro amarelo (ETc) durante 180 dias após o transplantio das mudas no campo, obteve um consumo de água de 4,68 mm.dia ${ }^{1}$, com os valores de Kc entre 0,51 e 1,10.

Sousa et al. (2000), citados por Sousa (2000), determinaram os valores de Kc para o maracujazeiro a partir da ETc medida em lisímetros de drenagem e a ETo estimada pelos métodos de Penman-Monteith, Thornthwaite e Tanque classe "A". Os autores concluíram que os maiores valores de $\mathrm{Kc}(1,48)$ foram obtidos quando a ETo foi estimada pelo método de Thornthwaite. Para a estimativa da ETo a partir da evaporação do Tanque Classe "A" e pelo método de Penman-Monteith, os valores máximos de $\mathrm{Kc}$ foram de 1,24 e 1,16, respectivamente.

O presente trabalho tem como objetivo quantificar a evapotranspiração máxima (ETc) e os coeficientes de cultivos (Kc) do maracujazeiro amarelo seleção Sul-Brasil, cultivado sob irrigação localizada mo município de Botucatu-SP.

\section{MATERIAL E MÉTODOS}

A experimentação foi conduzida na área experimental do Departamento de Engenharia Rural da Faculdade Ciências
Agronômicas - FCA, da Universidade Estadual Paulista-UNESP, Campus de Botucatu-SP, $\left(22^{\circ}\right.$ 51'03' 'de latitude sul, $48^{\circ} 26^{\prime} 37^{\prime}$ 'de longitude oeste, e $786 \mathrm{~m}$ de altitude).

O solo do local é classificado como Terra Roxa Estruturada, intergrade para Latossolo Vermelho Escuro, distrófico e de textura média argilosa (CARVALHO et al., 1983).

O preparo do solo consistiu de uma gradagem com posterior aplicação $\mathrm{e}$ incorporação de calcário dolomítico na quantidade determinada em função da análise química do solo para elevar a saturação de base para $80 \%$. As demais adubações seguiram as recomendações de Piza Jr. (1996). As covas foram abertas com $50 \mathrm{~cm}$ de diâmetro e $40 \mathrm{~cm}$ de profundidade no espaçamento de $3,5 \mathrm{~m}$ entre linhas e 3,0m entre plantas para as de bordadura e apenas uma planta por lisímetro. As mudas foram transplantadas em 21 de setembro de 2000 .

As mudas de maracujá foram conduzidas no sistema de espaldeira vertical. As plantas foram individualizadas com $o$ desbrote dos ponteiros dos dois ramos secundários quando estes alcançaram a planta vizinha à aproximadamente $2,0 \mathrm{~m}$ na horizontal. A poda do ramos terciários foi feita antes que estes atingissem o solo, em torno de 10-15 cm da superfície. O controle de ervas daninhas foi feita através de capina manual. As aplicações de inseticidas e fungicidas foram conduzidas de conformidade com as recomendações do Departamento de Defesa Fitossanitária desta Faculdade.

Durante o estádio de florescimento da cultura, utilizou-se a prática da polinização manual de acordo com a recomendações de Meletti \& Maia (1999). A colheita dos frutos estendeu-se desde 15 de março até 21 de agosto de 2001, sendo o pico da produção durante os meses de abril e maio quando a colheita passou a ser a cada 2-3 dias.

A irrigação foi procedida por gotejamento com emissores autocompensantes, um por planta, para as plantas da bordadura. Estas, bem como as dos lisímetros, tiveram avaliação dos potenciais e teores de água do solo por tensiômetros e com a curva característica de água do solo que foi 
determinada com placas de Richards. Os seguintes resultados médios foram obtidos para a camada de $0-20 \mathrm{~cm}$ para os teores, medidos em porcentagem com base peso de solo seco, de 23,$40 ; 22,70 ; 20,10 ; 18,80 ; 15,30 ; 15,20$; e $15,10 \%$, respectivamente para os potenciais de água do solo de $10 ; 20 ; 30$ 50; 600; 1000; e $1500 \mathrm{kPa}$. Para estes mesmos potenciais, corresponderam os valores de 23,$50 ; 22,30$; 21,$20 ; 20,70 ; 16,50 ; 16,00 ;$ e $15,10 \%$, respectivamente, porém à profundidade de 20 $40 \mathrm{~cm}$.

A evapotranspiração da cultura (ETc) e a evapotranspiração de referência (ETo) foram medidas em lisímetros com nível do lençol freático constante. As plantas fora dos lisímetros foram irrigadas utilizando-se gotejadores autocompensantes com vazão de 4 $\mathrm{L} \mathrm{h}^{-1}$. Para a medição da Evapotranspiração de Referência, foram usados dois lisímetros gramados com grama batatais. Três outros lisímetros foram usados para medir a Evapotranspiração Máxima da cultura. As médias simples de decênios foram usadas para as avaliações.

Foram usados lisímetros de cimentoamianto impermeabilizados internamente e com as dimensões de $0,75 \mathrm{~m}$ de altura, $1,15 \mathrm{~m}$ de largura e $1,60 \mathrm{~m}$ de comprimento. $\mathrm{Na}$ parte inferior tinha um sistema de drenagem com três tubos perfurados, envolvidos com brita e cobertos com material filtrante, Bidim-P 30. Os lisímetros eram conectados a um sistema para manutenção da altura do lençol freático com conexões de plástico, reservatório e bóia. A altura do lençol era diferenciada em função do desenvolvimento radicular da cultura e, a partir dos 120 dias após o transplante, foi mantido a $40 \mathrm{~cm}$ da superfície do solo. As leituras das perdas de água eram diárias e lidas em mangueira transparente acoplada ao tubo reservatório.

As medidas diárias da Evapotranspiração de Referência obtidas nos lisímetros com grama batatais e da Evapotranspiração Máxima da cultura, também em lisímetros, tiveram inicio oito dias após o transplantio das mudas no campo, donde foram obtidos os valores de $\mathrm{Kc}=\mathrm{ETc}_{\mathrm{ETo}}{ }^{-1}$.

\section{RESULTADO E DISCUSSÃO}

Os valores médios diários expressos em decênios da evapotranspiração do maracujazeiro amarelo e da evapotranspiração de referência medidas em três lisímetros de nível do lençol freático constante, durante o primeiro ano de produção da cultura são apresentados Figura 1.

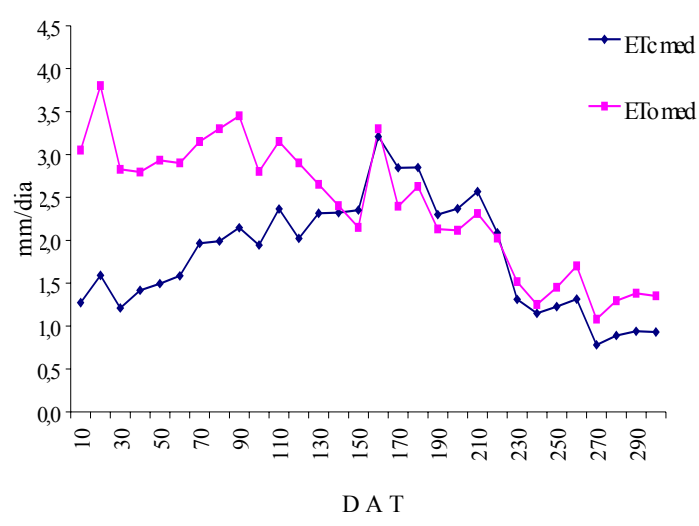

Figura 1. Variação temporal dos valores médios diários, expressos em decênios, da evapotranspiração de referência (ETo) e da evapotranspiração do maracujá amarelo (ETc), medidas em lisímetros durante o período de 29 de setembro de 2000 a 23 de julho de 2001 no município de Botucatu-SP.

A soma dos valores diários da evapotranspiração da cultura (média dos três lisímetros) desde o $10^{\circ}$ dia após o transplantio das mudas (DAT) no campo até à maturação dos últimos frutos foi de $954,98 \mathrm{~mm}$. Neste mesmo período, a evapotranspiração de referência (ETo) foi de 1.069,21 mm.

Os maiores valores de ETc, entre 2,32 $\mathrm{mm} /$ dia e $3,21 \mathrm{~mm} /$ dia, ocorreram entre 150 e 210 DAT que corresponderam aos estádios de floração, formação e maturação dos frutos (Quadro 2). Os valores da ETc foram inferiores aos encontrados por Alencar (2000) e Corrêa et al. (2001), determinados para as condições edafoclimáticas de município de Piracicaba, e aos consumos de água relatados por Martins (1998), Carvalho et al. (2000) e Sousa (2000). 
As diferenças entre os valores de demanda hídrica da cultura são decorrentes, dentre outros fatores, das diferenças entre a época de plantio, das características fisiológicas inerentes às "variedades" e das condições edafoclimáticas locais.

Os valores de Kc aumentaram com o desenvolvimento da cultura até 230 DAT. A partir desta data observou-se um decréscimo paulatino de Kc até atingir valores em torno de 0,69 (Figura 2). Nesta ocasião, devido às condições climáticas locais, houve um decréscimo acentuado na emissão de ramos novos e na abertura das flores. Os valores máximos de $\mathrm{Kc}$ ocorreram entre 150 e 210 DAT, nos estádios correspondentes à floração, formação e maturação dos frutos. Nesta fase de desenvolvimento da cultura, observaram-se acúmulo máximo de área foliar e de produção de frutos que, de acordo com Haag et al. (1973), ocorre em torno dos 240 DAT.

Quadro 1. Evapotranspiração de referência medida (ETo) durante o período de 29 de setembro de 2000 a 23 de julho de 2001 no município de Botucatu-SP.

\begin{tabular}{|c|c|c|c|c|}
\hline DAT & $\begin{array}{c}\text { Período } \\
\text { (dias) }\end{array}$ & $\begin{array}{l}\text { Eto Lis } 1 \\
(\mathrm{~mm} / \mathrm{dia})\end{array}$ & $\begin{array}{l}\text { Eto Lis } 2 \\
(\mathrm{~mm} / \text { dia })\end{array}$ & $\begin{array}{c}\text { ETo med } \\
\text { Lis } 1 \text { - Lis } 2 \\
(\mathrm{~mm} / \text { dia })\end{array}$ \\
\hline 10 & $29 / 09$ a $08 / 10 / 00$ & 3,12 & 2,98 & 3,05 \\
\hline 20 & $09 / 10$ a $18 / 10 / 00$ & 4,00 & 3,60 & 3,80 \\
\hline 30 & $19 / 10$ a $28 / 10 / 01$ & 3,15 & 2,50 & 2,83 \\
\hline 40 & $29 / 10$ a $07 / 11 / 02$ & 2,58 & 3,01 & 2,80 \\
\hline 50 & $08 / 11$ a $17 / 11 / 00$ & 3,46 & 2,40 & 2,93 \\
\hline 60 & $18 / 11$ a $27 / 11 / 00$ & 3,00 & 2,80 & 2,90 \\
\hline 70 & $28 / 11$ a $07 / 12 / 00$ & 3,70 & 2,60 & 3,15 \\
\hline 80 & $08 / 12$ a $17 / 12 / 00$ & 3,70 & 2,90 & 3,30 \\
\hline 90 & $18 / 12$ a $27 / 12 / 00$ & 3,80 & 3,10 & 3,45 \\
\hline 100 & $28 / 12$ a $06 / 01 / 01$ & 3,20 & 2,40 & 2,80 \\
\hline 110 & $07 / 01$ a $16 / 01 / 01$ & 3,70 & 2,60 & 3,15 \\
\hline 120 & $17 / 01$ a $25 / 01 / 01$ & 3,70 & 2,10 & 2,90 \\
\hline 130 & $26 / 01$ a $04 / 02 / 01$ & 3,40 & 1,90 & 2,65 \\
\hline 140 & $05 / 02$ a $14 / 02 / 01$ & 2,60 & 2,20 & 2,40 \\
\hline 150 & $15 / 02$ a $24 / 02 / 01$ & 3,00 & 1,30 & 2,15 \\
\hline 160 & $25 / 02$ a $06 / 03 / 01$ & 3,60 & 3,00 & 3,30 \\
\hline 170 & $07 / 03$ a $16 / 03 / 01$ & 2,69 & 2,10 & 2,40 \\
\hline 180 & $17 / 03$ a $26 / 03 / 01$ & 3,45 & 1,80 & 2,63 \\
\hline 190 & $27 / 03$ a $05 / 04 / 01$ & 2,76 & 1,50 & 2,13 \\
\hline 200 & $06 / 04$ a $15 / 04 / 01$ & 2,83 & 1,40 & 2,12 \\
\hline 210 & $16 / 04$ a $25 / 04 / 01$ & 2,72 & 1,90 & 2,31 \\
\hline 220 & $26 / 04$ a $05 / 05 / 01$ & 2,80 & 1,25 & 2,03 \\
\hline 230 & $06 / 05$ a $15 / 05 / 01$ & 1,83 & 1,20 & 1,52 \\
\hline 240 & $16 / 05$ a $25 / 05 / 01$ & 1,30 & 1,20 & 1,25 \\
\hline 250 & $26 / 05$ a $03 / 05 / 01$ & 1,70 & 1,20 & 1,45 \\
\hline 260 & $04 / 06$ a $13 / 06 / 01$ & 2,00 & 1,40 & 1,70 \\
\hline 270 & $14 / 06$ a $23 / 06 / 01$ & 1,56 & 0,60 & 1,08 \\
\hline 280 & $24 / 06$ a $03 / 07 / 01$ & 1,69 & 0,90 & 1,30 \\
\hline 290 & $04 / 07$ a $13 / 07 / 01$ & 1,46 & 1,30 & 1,38 \\
\hline 300 & $14 / 07$ a $23 / 07 / 01$ & 1,10 & 1,60 & 1,35 \\
\hline Média & & 2,79 & 2,02 & 2,41 \\
\hline
\end{tabular}


Quadro 2. Evapotranspiração máxima do maracujazeiro (ETc) medida em lisímetros, durante o período de 29 de setembro de 2000 a 23 de julho de2001, no município de Botucatu-SP.

\begin{tabular}{cccccc}
\hline DAT & $\begin{array}{c}\text { Período } \\
\text { (dias) }\end{array}$ & $\begin{array}{c}\text { ETc Lis } 1 \\
(\mathrm{~mm} / \mathrm{dia})\end{array}$ & $\begin{array}{c}\text { ETc Lis } 2 \\
(\mathrm{~mm} / \mathrm{dia})\end{array}$ & $\begin{array}{c}\text { ETc Lis } 3 \\
(\mathrm{~mm} / \mathrm{dia})\end{array}$ & $\begin{array}{c}\text { ETc (Lis1-Lis2-Lis3) } \\
(\mathrm{mm} / \mathrm{dia})\end{array}$ \\
\hline 10 & $29 / 09$ a 08/10/00 & 1,28 & 0,92 & 1,62 & 1,27 \\
20 & $09 / 10$ a $18 / 10 / 00$ & 1,62 & 1,90 & 1,25 & 1,59 \\
30 & $19 / 10$ a 28/10/01 & 1,20 & 1,21 & 1,21 & 1,21 \\
40 & $29 / 10$ a 07/11/02 & 1,43 & 1,70 & 1,12 & 1,42 \\
50 & $08 / 11$ a 17/11/00 & 1,47 & 1,52 & 1,49 & 1,49 \\
60 & $18 / 11$ a 27/11/00 & 1,60 & 1,28 & 1,89 & 1,59 \\
70 & $28 / 11$ a 07/12/00 & 1,95 & 1,95 & 1,98 & 1,96 \\
80 & $08 / 12$ a $17 / 12 / 00$ & 2,01 & 1,98 & 1,98 & 1,99 \\
90 & $18 / 12$ a 27/12/00 & 2,16 & 2,07 & 2,21 & 2,14 \\
100 & $28 / 12$ a 06/01/01 & 1,96 & 1,93 & 1,93 & 1,94 \\
110 & $07 / 01$ a 16/01/01 & 2,36 & 2,39 & 2,33 & 2,36 \\
120 & $17 / 01$ a 25/01/01 & 2,18 & 1,86 & 2,03 & 2,02 \\
130 & $26 / 01$ a 04/02/01 & 2,36 & 2,25 & 2,33 & 2,31 \\
140 & $05 / 02$ a 14/02/01 & 2,28 & 2,45 & 2,25 & 2,32 \\
150 & $15 / 02$ a 24/02/01 & 2,95 & 2,21 & 1,90 & 2,35 \\
160 & $25 / 02$ a 06/03/01 & 3,83 & 3,80 & 2,00 & 3,21 \\
170 & $07 / 03$ a 16/03/01 & 2,75 & 2,78 & 3,00 & 2,84 \\
180 & $17 / 03$ a 26/03/01 & 3,15 & 2,99 & 2,40 & 2,85 \\
190 & $27 / 03$ a 05/04/01 & 2,53 & 2,36 & 2,00 & 2,30 \\
200 & $06 / 04$ a 15/04/01 & 2,51 & 2,50 & 2,10 & 2,37 \\
210 & $16 / 04$ a 25/04/01 & 2,73 & 2,99 & 1,98 & 2,57 \\
220 & $26 / 04$ a 05/05/01 & 2,33 & 2,33 & 1,60 & 2,09 \\
230 & $06 / 05$ a 15/05/01 & 1,52 & 1,36 & 1,05 & 1,31 \\
240 & $16 / 05$ a 25/05/01 & 1,23 & 1,20 & 1,02 & 1,15 \\
250 & $26 / 05$ a 03/05/01 & 1,29 & 1,46 & 0,92 & 1,23 \\
260 & $04 / 06$ a 13/06/01 & 1,53 & 1,51 & 0,90 & 1,31 \\
270 & $14 / 06$ a 23/06/01 & 0,81 & 0,81 & 0,72 & 0,78 \\
280 & $24 / 06$ a 03/07/01 & 0,91 & 0,91 & 0,85 & 0,89 \\
290 & $04 / 07$ a 13/07/01 & 0,90 & 0,85 & 1,07 & 0,94 \\
300 & $14 / 07$ a 23/07/01 & 1,05 & 0,90 & 0,85 & 0,93 \\
\hline Média & & 1,90 & 1,88 & 1,64 & 1,82 \\
\hline
\end{tabular}

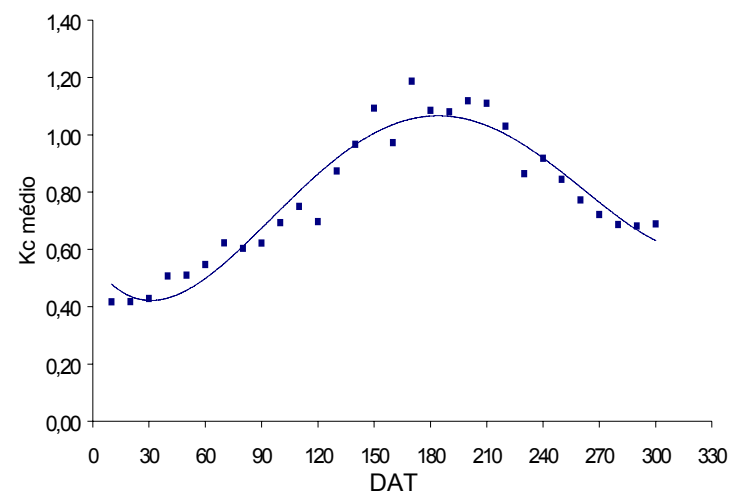

Figura 2. Variação do coeficiente de cultivo (Kc) ao longo do ciclo da cultura do maracujá amarelo durante o primeiro ano de produção.
Considerando-se as médias por décadas, o maior valor de $\mathrm{Kc}(1,18)$ ocorreu entre 200 e 210 DAT, valores inferiores aos obtidos por Alencar (2000) e próximos aos encontrados por Sousa (2000), quando obteve os valores de Kc através da relação ETc medida pela ETo estimada pelos métodos de PenmanMonteith e do Tanque classe "A" que, nas condições deste experimento superestimaram a ETo medida nos lisímetros, durante todo o período de desenvolvimento da cultura 


\section{CONCLUSÕES}

A demanda hídrica da cultura medida durante o período de 29 de setembro de 2000 à 31 de julho de 2001 foi de 954,98 mm. Os valores de Kc variaram de 0,42 a 1,12, com valor máximo registrado entre 200 e 210 DAT.

\section{REFERÊNCIAS BIBLIOGRÁFICAS}

ALENCAR, C. de A. Consumo de água do maracujazeiro amarelo (Passiflora edulis Sins var. flavicarpa Deg.). 2000, 49 f. Dissertação (Mestrado em Agronomia Irrigação e Drenagem). Escola Superior de Agricultura "Luiz de Queiroz", Universidade de São Paulo, Piracicaba, 2000.

CARVALHO, A. J. C. de et al. Adubação nitrogenada e irrigação no maracujazeiroamarelo. I. Produtividade e qualidade dos frutos. Pesquisa Agropecuária Brasileira, Brasília, v. 35, n. 6, p. 1101-1108, 2000.

CORRÊA , R. A. de et al. Consumo hídrico do maracujazeiro amarelo no primeiro ano de produção. In: CONGRESSO BRASILEIRO DE AGROMETEOROLOGIA, 12., REUNIÃO LATINO AMERICANA DE AGROMETEOROLOGIA, 3., 2001, Fortaleza. Anais... Santa. Maria: Sociedade Brasileira de Agrometeorologia, 2001. p. 423-424.

HAAG, H. P. et al. Absorção de nutrientes por duas variedades de maracujá. Anais da Escola Superior de Agricultura "Luis de Queiroz", Universidade de São Paulo, Piracicaba, v. 30, p. $267-279,1973$
MARTINS, D. P. Resposta do maracujazeiro amarelo (Passiflora edulis Sims var. flavicarpa Deg) a lâminas de irrigação e doses de nitrogênio e potassio. 1998, Tese (Doutorado em Produção Vegetal). Centro de Ciências e Tecnologia da Universidade Estadual do Norte Fluminense, Campos dos Goytacases, 1998.

MELETTI, L. M. M.; MAIA, M. L. Maracujá: produção e comercialização. Boletim Técnico do Instituto Agronômico, Campinas, n. 181, p. 1-64.

MENZEL, C. M; SIMPSON, D. R; PRINCE, G. H. Effect of foliar applied nitrogen during winter on growth, nitrogen content and production of passionfruit. Scientia Horticulturae, Amsterdam, v. 28, n. 4, p. 339346, 1986.

PIZA JUNIOR, C. de T. et al. (Ed.) Recomendações de calagem e adubação para o Estado de São Paulo. Boletim Técnico do Instituto Agronômico, Campinas, n. 100, p. 148-149, 1996.

SOUSA, V. S. Níveis de irrigação e doses de potássio aplicadas via fertirrigação por gotejamento no maracujazeiro amarelo (Passiflora edulis Sins var. flavicarpa Deg.). 2000, 145 f. Tese (Doutorado em Agronomia Irrigação e Drenagem). Escola Superior de Agricultura "Luiz de Queiroz", Universidade de São Paulo, Piracicaba, 2000.

STAVELY, G.W.; WOLSTENHOLME, B.N. Effects of water stress on growth and flowering of Passiflora edulis (Sims) grafted to P.Caerulea L. Acta Horticulturae, Leuven, v. 75, n. 2, p. 251-258, 1990. 